\title{
Promoting Course Teaching Level of "Mechanical Design, Manufacturing and Automation" Specialty Based on ABET Concepts
}

\author{
Liangwen Wang * \\ Zhengzhou University of Light Industry \\ School of Mechanical and Electrical Engineering \\ Zhengzhou 450002, China
}

\section{Wenliao Du}

Zhengzhou University of Light Industry

School of Mechanical and Electrical Engineering

Zhengzhou 450002, China

\author{
Hongwei Li \\ Zhengzhou University of Light Industry \\ School of Mechanical and Electrical Engineering \\ Zhengzhou 450002, China \\ Fannian Meng \\ Zhengzhou University of Light Industry \\ School of Mechanical and Electrical Engineering \\ Zhengzhou 450002, China
}

\author{
Guizhong Xie \\ Zhengzhou University of Light Industry \\ School of Mechanical and Electrical Engineering \\ Zhengzhou 450002, China
}

\begin{abstract}
In order to build the characteristic specialty of "mechanical design, manufacturing and automation" in Zhengzhou University of Light Industry a Chinese first-class major, based on the valuable experience in some American universities, the ABET (American engineering and technology certification commission) certification standards are used to improve the teaching level of the course. Firstly, the ABET certification standards are described, and compared with the general engineering education certification standards in China. And then, some improved teaching theories and practices of the specialty have been proposed to achieve the course goals more guaranteed, which include making clear course objectives and strict implementing steps, choosing specialty core courses, strengthening teaching process management, performing a thirdparty appraisal of teaching process, changing the evaluation method of courses teaching, etc. Finally, the effect of implementation is summarized. The idea of the paper can provide some beneficial references for similar specialty to improve the course teaching level and pass the ABET certification.
\end{abstract}

Keywords-ABET certification; Chinese engineering education accreditation; Curriculum system; Course teaching improvement; Characteristic specialty construction

\section{INTRODUCTION}

ABET specializes in the engineering and technology education certification in the four fields of academic institutions, which is internationally recognized as one of the most authoritative certification bodies[1-2]. As a third-party organization that is independent of the government and the market system, ABET has a very significant performance for

Higher Education Teaching Reform Project in Henan Province (2017SJGLX358) participating in higher education evaluation. ABET certification in the United States is not an official body, the application for certification is voluntary, and the certification conclusion is only passed or not passed. After passing the certification, the colleges and universities are inspected every year. There is no limit to the number of passes, and its certification is generally recognized. Therefore, many American colleges and universities take the initiative to apply for certification. China's engineering education certification has strong Chinese characteristics. The certification body is an official, and the application for certification is voluntary. However, considering the actual situation of China, in principle, no more than $20 \%$ of the total number of specialty for colleges and universities in China can pass the certification, so it is more challenging.

At present, the "mechanical design, manufacturing and automation" specialty in Zhengzhou University of Light Industry is the only mechanical specialty that maintains the characteristics of the light industry in China. Around the orientation of school-running and development planning, three specialty directions, including mechanical design and automation, mechanical manufacturing automation, mechanical and electrical engineering, have been formed, which emphasize on the cultivation of talents for light industrial machinery, and have a certain influence in the industry.

In constructing our specialty, the education model is constantly studied, adjusted and continuously improved according to the development of the society. In 2018, the "mechanical design, manufacturing and automation "specialty 
in Zhengzhou University of Light Industry has passed China's Engineering education professional certification. In order to construct the specialty to be influential in the Industry, on the basis of the ABET certification requirements, we have continuously improved the teaching process of the "mechanical design, manufacturing and automation "specialty in the Zhengzhou University of Light Industry. In this paper, our researches and practices focus on the realization of course teaching objectives. Some measures have been proposed to achieve the course teaching goal, which include making the clear course teaching objectives and strict implementing, selecting the 6 to 8 major core courses for the key evaluation and tracking, strengthening the course teaching process management to reduce the proportion of the final examination result, performing a third party appraisal for teaching process, changing the evaluation of courses teaching as combination of learning and teaching evaluation, perfecting system construction to guide the development and teaching process of relevant courses, strengthening the topic selection of graduation design. We carry out a beneficial exploration to promote curriculum teaching level for the "mechanical design, manufacturing and automation" characteristic specialty.

\section{RELATED STANDARDS OF ABET CERTIFICATION AND DIFFERENCES WITH STANDARDS OF CHINESE ENGINEERING EDUCATION CERTIFICATION}

ABET certification activities focus on ensuring the quality of education, encouraging educational innovation, and emphasizing the improvement of students outcomes through certification. In order to achieve the ultimate pursuit of quality, ABET's evaluation concept has undergone a transformation from input-based to output-based. The common standard of the ABET certification includes 8 aspects[3], as follows: (1) students, (2) Program educational objectives, (3) student outcomes, (4) continuous improvement, (5) curriculum, (6) faculty, (7) teaching resources, (8) Institutional Support.

From the view of the ABET certification standard, there is little difference between Chinese engineering education certification standard. There are 8 general standards for ABET and 7 general standards for the engineering education certification in China. The first 6 items have the same names. Requirements of the items 7 and 8 of the ABET standards are basically the same with item 7 in the standard of China engineering education certification.

There are 12 graduation requirements for the engineering education certification in China, each has 2 to 4 specific connotations, further. Graduation requirements of ABET are only 7 , each of which has rich connotations. The course systems of the two certification standards are required to support graduation requirements. The supporting materials required by the two systems are basically the same, which satisfy the substantial equivalence of the engineering certification concept.

\section{REQUIREMENTS FOR STUDENTS OUTCOMES}

According to relevant information, students outcomes for ABET certification include 11 items[4], as follows:

(a) The ability to apply knowledge of mathematics, science and engineering. (b) The ability to design, control experiments and analyze and interpret data.

(c) The ability to design a system, part or process which meets the constraints of many practical conditions, such as politics, ethics, health and safety, manufacturability and sustainability.

(d) The ability to function in interdisciplinary teams.

(e) The ability to identify, construct and solve engineering problems.

(f) The ability to understand the professional spirit and moral responsibility.

(g) The ability to communicate effectively.

(h) The broad knowledge to understand the impact of engineering solutions in a global economic, environmental and social context.

(I) A clear awareness of the importance of lifelong learning and the ability to learn for life.

(j) An understanding of major contemporary issues.

(k) The ability to apply the necessary technologies, skills, and advanced equipment in engineering practice, etc.

In addition to these 11 competencies, any special skills required for the relevant research area as specified in the professional standards can be added. In ABET certification, students outcomes are the focus of attention. The primary goal of the certification is to ensure that students have fully prepared for the professional field on their graduation.

\section{IMPROVING THE TEACHING PROCESS TO ACHIEVE THE COURSE OBJECTIVES OF "MECHANICAL DESIGN, MANUFACTURING, AND AUTOMATION" SPECIALTY}

ABET certification focuses on students' outcomes. Students' learning needs self-construction, which is a process of internalizing external knowledge into their own knowledge structure. Teachers need to provide self-constructed teaching activities for students so that students can grow and create. Based on the beneficial practice of ABET certification in course teaching of some American universities, the reforms of the course teaching process of "machine design, manufacturing and automation" specialty in Zhengzhou University of the light industry have been carried out as follows[5-8].

\section{A. Defining course objectives and strictly implementing}

Teachers in our specialty introduce the objectives, plans, requirements and contents of the course to the students before the teaching course starts, and ask the students to follow the requirements strictly. All course objectives need to be converted into the evaluable target. The students should be cultivated in a stable evaluation system. Therefore, the evaluation process should distinguish and clarify what is measurable or unmeasurable for the course objectives, and convert the unmeasurable parts into measurable ones, firstly. 


\section{B. Selecting core courses for evaluation}

In the "mechanical design, manufacturing and automation" specialty, 6 to 8 courses are selected to carry out the reforms of course scores and course evaluation. The 5 courses have been chosen, including Mechanical Drawing, Theoretical Mechanics, Material Mechanics, Mechanical Principles, and Mechanical Parts, firstly. Because our specialty has three specialized directions, including machine design and automation, machinery manufacturing and automation, mechanical and electronic engineering, we choose one major core course each in one direction.

\section{Strengthening process management in course teaching}

Teachers in our specialty change the composition of students' scores including the homework, classroom test, major engineering design, final examination, etc, significantly increase the number of classroom tests, and reduce the proportion of final examination.

\section{Performing a third-party appraisal of the teaching process}

Other teachers or course teaching groups are adopted to conduct evaluation and inspection. The course teacher should provide all the materials of good, medium and poor students in the course. The third party or the department organizes other teachers to evaluate the teaching process of teachers and the grading of students. Concretely speaking, the course teacher provides all the materials representing good, medium and poor learning status of students in the course, including the homework, in-class test, the major engineering design, the course final examination and other materials. The third-party evaluates the teaching process of the course teacher and the grading status of students. In the course material inspection and evaluation, the evaluation scores are divided into 1,2,3,4 and 5 . The course teacher who's score below 4 should explain and give the corrective measures.

\section{E. Changing the teaching evaluation of courses}

We have changed teaching evaluation of courses into the evaluation combining learning and teaching. The teaching evaluation system of the course included: (a) defining the detailed objectives and knowledge points of the course teaching. Students made an evaluation for their own learning and mastery according to knowledge points. (b) students evaluated the whole teaching activities of the courses, including the process of giving the class, the teacher teaching, learning process of the students themselves including learning expectation, experiment, examination, homework and extracurricular reading, etc. (c) developing the communication and interaction between students and teachers.

When Students have evaluated courses online, the questions involved are broader. The questions surveyed included: (a) Did the teacher make students clear about the course objectives? (b) Did the teacher teach in a clear and organized manner? (c) Did the teacher develop students' interest in learning? (d) Did the teacher motivate students to study as hard as they could? (e)Was the teacher willing to help students out of class? (f) Did the student have the ability to deal with problems using knowledge learned from the class? (g) How was the use of teachers' time in class? (h) How was about use of blackboard, PPT and other auxiliary tools? (I)
How was about consistency and fairness of the scores? (j) How was the timeliness of feedback such as homework? (k) How was an overall evaluation for teachers? (l) How helpful were teaching materials to the course? (m) What was the student's overall evaluation of the course as a learning experience? (n) How much time did the student spend on this course outside class every week? (o) What was a student's expected score? (p) What other comments did students have about the teacher? (q) What other comments did students have on the course, etc.

\section{F. Improving the curriculum responsible person system}

On the basis of improving the curriculum principal system, a number of curriculum teaching guidance committees were set up to guide the development and teaching process of relevant courses.

\section{G. Strengthening the topic selection of graduation project}

The graduation design topic for "mechanical design, manufacturing and automation" specialty and others reduced the thesis type topic. In the initial stage, the thesis type topic cannot exceed 1 to 2 for each advisor in giving the graduation design topic. Eventually, the graduation design topic must be an engineering design type topic. Graduation design topics from enterprises have been encouraged and making system and actual samples are welcomed to avoid selecting the big and empty topic.

\section{H. Cultivating the teamwork awareness and some ability to understanding non-technical influence factors}

In the course design and graduation design, the design mode of grouping and sub-team is implemented, and the mutual evaluation of students is added. The writing report strengthens the understanding of the non-technical influence factors such as professional skills and professional ethics.

\section{Strengthening connections with enterprises}

In terms of teacher introduction, high-level teachers are introduced from enterprises to supplement the teaching team. Meanwhile, teachers with corporate backgrounds with enterprises have been increased by encouraging them to take part-time jobs in enterprises. Enterprise engineers are encouraged to participate in the guidance of graduation design. There are strict rules and measures to standardize the whole process.

\section{J. Laboratory construction and development}

We have opened lab facilities for all students and extend lab development time. Each large instrument is managed by a special person, and students can operate it at any time under the guidance of teachers

\section{K. Realizing the continuation of course learning and early warning}

The course setting is modular and progressive. The precourse has not been studied or the study is unqualified, the student cannot carry on studying the follow-up course. The students flunked a course and had to repeat it. If students fail in two courses, early warning is given. Each course is allowed to repeat only once, and students who repeat three times are required to drop out. 


\section{Cultivating the lifelong learning ability}

In major engineering design and the graduation design, for the student's questions, teachers guide students to consult materials independently, instead of giving answers directly, and consciously to cultivate their lifelong learning ability.

\section{CONCLUSION}

Through continuous improvement in the certification process, the ABET concepts have been adopted to improve the course teaching level of "mechanical design, manufacturing and automation" specialty in Zhengzhou University of Light Industry. The teaching quality of specialty has been significantly improved. In the specialty evaluation of Henan province, this specialty was awarded excellent. Taking the design, manufacture and control of light industry machinery, especially packaging machinery and automatic machinery, as the characteristic, the " mechanical design, manufacturing and automation" specialty in Zhengzhou University of Light Industry possesses the foundation and ability with a certain influence in China. We are striving to build this specialty into a first-class major in China.

\section{REFERENCES}

[1] History. Http://www.abet.org/about-abet/history/.2018-1-14

[2] Prados J W, Peterson G D, Lattuca LR. Quality assurance of engineering education through accreditation: The impact of Engineering Criteria 2000 and its global influence. Journal of engineering education, 2005, 94 (1):165-184.

[3] ABET Engineering Accreditation Commission, criteria for accrediting engineering programs, Website: www.abet.org, 10/ 20/ 2017

[4] Teng Jin-fang, Course Improvement Based on the Student Outcomes of ABET Certification Standard. Education teaching forum(In Chinese), Apr. 2018 NO.17, 119-120.

[5] Liang-wen Wang, Feng Zhao, Wen-liao Du, and Guo-fu Luo. "Teaching reform and practice of the curriculum of mechanism design based on innovation ability training," 2016 International Conference on Advanced Education and Management (ICAEM 2016). Hangzhou, pp. 259-264, May 2016.

[6] Liang-wen Wang, Fan-nian Meng, Guo-fu Luo, Cai-dong Wang, and Wen-liao Du, Students' Graduation Project Training for Mechanical Design Specialty Based on Light Industries Transformation, 2017 2nd International Conference on Education, E-learning and Management Technology (EEMT 2017), Xi'an, China. pp. 705-710, Jul 2017.

[7] Gui-zhong Xie, Fan-nian Meng, De-hai Zhang, Liang-wen Wang, Feng Zhao and Hao Li. Research of Course Teaching System Reform with the Characteristic of Light Mechanism Design[C]. 2017 2nd International Conference on Education, E-learning and Management Technology (EEMT 2017), Xi'an, China. pp. 721-724, Jul 2017.

[8] Feng Zhao, Liang-wen Wang, Gui-zhong Xie and Fan-nian Meng. Application-oriented Three-dimensional Training Mode for the Limits and Fits Curriculum of Mechanical Engineering[C]. 2018 3rd Annual International Conference on Education Science and Education Management (ESEM 2018), Wuhan, China. pp. 275-278, April 20-22, 2018. 